\title{
ANTIOXIDANT ACTIVITIES AND TOTAL PHENOLIC AND FLAVONOID CONTENT VARIATIONS OF LEAF EXTRACTS OF LAURUS NOBILIS L. FROM MOROCCO
}

\author{
AMAL TAROQ*, FATIMA EL KAMARI, IMANE AOUAM, YASSINE EL ATKI, BADIAA LYOUSSI, \\ ABDELFATTAH ABDELLAOUI
}

\begin{abstract}
Department of Biology, Laboratory of Physiology Pharmacology and Environmental Health, Faculty of Sciences Dhar Mehraz, Sidi Mohamed Ben Abdellah University, B.P. 1796, Atlas, Fez, Morocco. Email: taroq.amal@gmail.com
\end{abstract}

Received: 14 September 2018, Revised and Accepted: 23 October 2018

ABSTRACT

Objective: The present study was undertaken to determine antioxidant activity and total phenolic and flavonoid content of ethanol, methanol, ethyl acetate, and aqueous extracts of the leaves of Laurus nobilis L.

Methods: Antioxidant properties were measured using three tests: Free radical scavenging activity against 2,2-diphenyl picrylhydrazyl (DPPH), reduction of molybdate, and reducing $\left(\mathrm{Fe}^{3+} / \mathrm{Fe}^{2+}\right)$ power. Total phenolic and flavonoid content was measured by Folin-Ciocalteu and rutin reagent, respectively.

Results: The results showed that both the ethanol and water extracts had greater antioxidant activity than ethyl acetate. Aqueous extract exhibited a higher DPPH radical scavenging and reducing molybdate $545.83 \pm 5.89 \mathrm{mg}$ equivalent to ascorbic acid/g dry extract. The strong antioxidant activity of water extract was probably due to its high content of phenols. Furthermore, ethanol and water extracts showed higher total flavonoid content with the values: $153.33 \pm 3.59$ and $127.25 \pm 2.60 \mathrm{mg}$ equivalent rutin/g dry extract, respectively.

Conclusion: Our results suggested a potent and excellent antioxidant activity of L. nobilis L. extracts of Morocco. Further research has to be done to isolate the pure bioactive compound and could be considered as a potential source of biomolecules for pharmaceutical and food industry.

Keywords: Laurus nobilis L., Antioxidant, 2,2-diphenyl picrylhydrazyl, Flavonoid, Phenolic.

(C) 2018 The Authors. Published by Innovare Academic Sciences Pvt Ltd. This is an open access article under the CC BY license (http://creativecommons. org/licenses/by/4. 0/) DOI: http://dx.doi.org/10.22159/ajpcr.2018.v11i12.29747

\section{INTRODUCTION}

The oxidative stress is mainly generated due to the disequilibrium between the production of reactive species and the organism defense. The excessive production of reactive species causes usually DNA and protein denaturation, lipid peroxidation, which induces chronic diseases such as cancer, diabetes as well as neurodegenerative and cardiovascular diseases [1]. Hence, an organism needs to synthesize antioxidant substances to tackle the production of free radicals. Given that the antioxidants are toxic, it is necessary to look for some natural antioxidants as an alternative pathway. Indeed, plants, being rich in terms of secondary metabolites (e.g., phenols and flavonoids), have several benefits on human public health $[2,3]$. These secondary metabolites are able to reduce different free radicals for further prevention from chronic diseases [4]. The growth of different plant organs depends ultimately on environmental conditions such as light, water, and soil nutrients. The genus Laurus is an evergreen Mediterranean tree. It is used usually as a condiment in traditional dishes. Several researches have reported on the essential oil of laurel. These studies have confirmed the great antibacterial, antifungal, and antioxidant potential of this oil [4-6]. Moreover, laurel oil could be used in conservation food process [7] and also as a biopesticide [8]. Conventionally, Laurus nobilis L. leaves could be used as aroma and are mainly exploited in traditional medicine for earache treatments and rheumatism and also could promote the transpiration process and blood infusion using its fruit which has diuretic and carminative effects. Several pharmaceutical studies have demonstrated that laurel might be used in diabetes treatment as well as cardiovascular diseases to improve the lipid profile in type 2 diabetes [9]. The aqueous laurel extract is characterized by remarkable healing activities [10] and by a gastroprotector effect [11,12]. Being rich in various secondary metabolites, the genus Laurus represents a great importance toward human disease treatments.
In this present study, we focused on the identification of laurel antioxidant properties. Thus, the major aim was to determine the different amounts of phenols and flavonoids in different extracts to select the best-extracted solvent, which has an antioxidant activity compared to the standard antioxidants.

\section{METHODS}

Reagents and standards

2,2-diphenyl picrylhydrazyl (DPPH), butylated hydroxytoluene (BHT), ammonium molybdate, sodium phosphate, sulfuric acid, gallic acid, $\mathrm{FeCl}_{3}, \mathrm{~K}_{3} \mathrm{Fe}(\mathrm{CN})_{6}$, and Folin-Ciocalteu reagent were purchased from Sigma-Aldrich (St. Louis, MO, USA). All the other chemicals and solvents used were of analytical grade.

Plant materials and preparation of extracts

Leaves of Laurier were collected in April 2014 from the region of Larache (Western Morocco) and dried for 2 weeks at ambient temperature. Identification was confirmed by Professor Amina Bari, botanist (Department of Biological Sciences, Faculty of Sciences Sidi Mohammed Ben Abdellah University, Fez, Morocco). $5 \mathrm{~g}$ of powder was extracted with $50 \mathrm{ml}$ of solvent (water, ethanol, methanol, and ethyl acetate) for $48 \mathrm{~h}$; then, the mixture was filtered through a filter paper (Whatman $\mathrm{N}^{\circ} 1$ ) and dried under vacuum at $45^{\circ} \mathrm{C}$ for further use.

\section{DPPH scavenging activity}

The ability of the extracts to scavenge the DPPH radical was measured using the method described by $\mathrm{Si}$ et al. [13], and $0.1 \mathrm{ml}$ of various concentrations of the extracts or standard was added to $1.5 \mathrm{ml}$ of ethanolic solution containing $0.1 \mathrm{mmol}$ of DPPH. The absorbance of the mixture was measured at $517 \mathrm{~nm}$ with a spectrophotometer (Jasco 
V-530) after 30 min of incubation time at room temperature in the dark. The percentage inhibition was calculated by the following equation:

$\left.I(\%)=\left(A_{b}-A_{s}\right) / A_{b}\right) \times 100$

Where $A_{s}$ is the absorbance of the control and $A_{b}$ is the absorbance of the sample. BHT served as positive control. The $\mathrm{IC}_{50}$ values were calculated as the concentration providing a $50 \%$ inhibition of DPPH radical.

\section{Reducing power capacity}

The reducing capacity of the tested extracts was determined in accordance with the procedure of Oyaizu [14]. $100 \mu \mathrm{l}$ of the extract was mixed with $500 \mu \mathrm{l}$ of phosphate buffer $(0.2 \mathrm{M}, \mathrm{pH} 6,6)$ and $500 \mu \mathrm{l}$ of potassium ferricyanide $\left(\mathrm{K}_{3} \mathrm{~F}_{\mathrm{e}}[\mathrm{CN}]_{6}\right) 1 \%$. The obtained solution was incubated at $50^{\circ} \mathrm{C}$ for $20 \mathrm{~min}$. The mixture was acidified with $500 \mu \mathrm{l}$ of trichloroacetic $10 \%$ which was then centrifuged at $3000 \mathrm{rpm}$ for $10 \mathrm{~min}$. The upper layer of the solution $(2.5 \mathrm{ml})$ was mixed with $500 \mu \mathrm{l}$ of distilled water and $100 \mu \mathrm{l}$ of $\mathrm{F}_{\mathrm{e}} \mathrm{Cl}_{3}(0,1 \%)$, and the absorbance was measured at $700 \mathrm{~nm}$ (Jasco v-530). BHT was used as standard. The results were expressed as $\mathrm{EC}_{50}(\mathrm{mg} / \mathrm{ml})$. $\mathrm{EC}_{50}$ (concentration corresponding 0.5 of absorbance) was calculated by plotting absorbance against the corresponding concentration. All samples were analyzed in triplicate.

\section{Total antioxidant capacity}

The assay was based on the reduction of $\mathrm{Mo}(\mathrm{VI})$ to $\mathrm{Mo}(\mathrm{V})$ and subsequent formation of a green phosphate/Mo(V) complex in acid $\mathrm{pH}$ [15]. A total volume of $25 \mu \mathrm{l}$ extracts dissolved in ethanol was added to $1 \mathrm{ml}$ of reagent solution $(0.6 \mathrm{~mol} / \mathrm{L}$ sulfuric acid, $28 \mathrm{mmol} / \mathrm{l}$ sodium phosphate, and $4 \mathrm{mmol} / \mathrm{l}$ ammonium molybdate). The mixtures were incubated at $95^{\circ} \mathrm{C}$ for $90 \mathrm{~min}$ and then cooled to room temperature. The absorbance was measured at $695 \mathrm{~nm}$ (Jasco v-530). The total antioxidant activity was expressed as the number of equivalence of ascorbic acid

\section{Determination of total phenolic compounds content}

Total phenolic content of the extract was determined by Folin-Ciocalteu method [16]. The $0.5 \mathrm{ml}$ of a known dilution of the extract and $2 \mathrm{ml}$ of $7 \%$ sodium carbonate solution were added to $2.5 \mathrm{ml}$ of $10 \%(\mathrm{v} / \mathrm{v}$ ) Folin-Ciocalteu reagent. The absorbance was read at $760 \mathrm{~nm}$ (Jasco $\mathrm{v}$-530) after $2 \mathrm{~h}$ of reaction at room temperature in the dark. Gallic acid was used as standard for the construction of calibration curve. Total phenol contents were expressed as milligrams of gallic acid equivalents per gram dry weight (mg GAE/g DM)

\section{Total flavonoids contents}

Total flavonoids contents of extracts were measured by the aluminum chloride colorimetric assay [17]. $1 \mathrm{ml}$ of sample or rutin standard solution was added into a $10 \mathrm{ml}$ volumetric flask containing $4 \mathrm{ml}$ of distilled water. To the flask, $0.30 \mathrm{ml} 5 \% \mathrm{NaNO}_{2}$ was added, and after $5 \mathrm{~min}, 0.3 \mathrm{ml} \mathrm{AlCl}_{3} 10 \%$ was added to react for $6 \mathrm{~min}$. After that, $2 \mathrm{ml}$ of $1 \mathrm{M} \mathrm{NaOH}$ was added and the total was made up to $10 \mathrm{ml}$ with distilled water. The solution was mixed and absorbance was measured against the blank at $510 \mathrm{~nm}$ (Jasco v-530). Rutin was used as standard for the construction of calibration curve. Total flavonoid contents were expressed as mg rutin equivalents per gram dry weight of each extract (mg RE/g DM). All samples were analyzed in triplicate.

\section{Statistical analysis}

Presented data are mean \pm standard deviation of three replicates. The results were compared by one-way analysis of variance. Tukey's test was used to test significant differences among the means. Differences among means at the $5 \%$ level $(\mathrm{p}<0.05)$ were considered statistically significant.

\section{RESULTS}

\section{Extraction yield}

As shown in Table 1, the extraction yield was determined by maceration method. Indeed $10 \mathrm{~g}$ of leaves powder was measured, the extraction based on the methanolic and ethanolic solvents showed the best extraction yield with $22 \%$ and $12 \%$, respectively, whereas the extraction based on ethyl acetate showed the lowest yield extraction with $6 \%$.

\section{DPPH scavenging activity}

The trapping test of the free radical DPPH, of the ethanolic, methanolic, ethyl acetate, and water extracts of L. nobilis L., compared to the BHT is shown in Table 2. The $\mathrm{IC}_{50}$ is defined as the sample concentration that could reduce $50 \%$ of DPPH. In this study, all extracts showed the ability to reduce DPPH. However, ethyl acetate has a reduction power similar to that of the standard antioxidant. The aqueous extract has a more efficient reducing power than the BHT with the values of $\mathrm{IC}_{50}=0.05 \pm 0.03 \mathrm{mg} / \mathrm{ml}$ and $\mathrm{IC}_{50}=0.10 \pm 0.001 \mathrm{mg} / \mathrm{ml}$, respectively, Table 2. Overall, ethanolic and methanolic extracts showed the lowest antiradical activity.

\section{The reducing power of iron}

The reducing properties are usually associated with the presence of certain compounds which could act by breaking the free radical chain, to provide an oxygen atom [11]. The presence of reducers in plant extracts induces generally the reduction of $\mathrm{Fe}^{3+}$ to $\mathrm{Fe}^{2+}$ form. This reduction could be compared to that of BHT, which is known as an efficient reducing agent. All laurel extracts have a reducing ability; however, the water extract has a high reducing ability equal to that of BHT as shown in Table 2. The ethyl acetate extract represents the lowest reducing power with $\mathrm{EC}_{50}=0.29 \pm 0.004 \mathrm{mg} / \mathrm{ml}$.

\section{Determination of total antioxidant capacity}

This quantitative method $[12,18]$ is mainly based on the reduction of molybdate (VI) to molybdate (V) in the presence of the extract, as well as the formation of a phosphate product $\mathrm{M}(\mathrm{V})$. The aqueous extract is characterized by a total antioxidant activity which is 5 times higher than that of the ethanolic and methanolic extract, whereas the acetate extract showed a lower total antioxidant activity with value 28.6 \pm 2.07 equivalent Vitamin C mg/g DM. The total antioxidant capacity was significantly higher in all extracts [Fig. 1]

\section{Total phenolic compound and flavonoid contents}

The total amounts of phenol were estimated by the Folin-Ciocalteu method for each extract and were expressed in mg of gallic acid/g of the dry plant. The amount of phenols in the L. nobilis L. extracts varies between $21 \pm 0.72$ and $494.86 \pm 3.62 \mathrm{mg}$ equivalent to gallic acid/g DM: Ethyl acetate $<$ methanolic $<$ ethanolic $<$ water extract. The aqueous extract has the highest amount in terms of phenols reaching $494.86 \pm 3.62 \mathrm{mg}$ equivalent to Gallic acid/g DM.

Table 1: Residues yields (\% of dry matter) of L. nobilis L. in the organic solvents

\begin{tabular}{ll}
\hline Type of extracts & Yields (\%) \\
\hline Ethanolic & 12 \\
Methanolic & 22 \\
Ethyl acetate & 6 \\
Water & 8 \\
\hline
\end{tabular}

L. nobilis: Laurus nobilis

Table 2: DPPH radical scavenging and reducing power activities of ethanol, ethyl acetate, and water extracts of leaves of laurel compared to BHT

\begin{tabular}{lll}
\hline Extracts & DPPH & FRAP \\
\hline Ethanolic & $0.48 \pm 0.019^{* * *}$ & $0.21 \pm 0.0006^{* * *}$ \\
Ethyl acetate & $0.10 \pm 0.006$ & $0.29 \pm 0.004^{* * *}$ \\
Water & $0.05 \pm 0.003^{* *}$ & $0.12 \pm 0.001$ \\
Methanolic & $0.31 \pm 0.009^{* * *}$ & $0.22 \pm 0.0005^{* * *}$ \\
BHT & $0.10 \pm 0.0001$ & $0.12 \pm 0.0001$ \\
\hline
\end{tabular}

All values are expressed as a mean of triplicate $\pm S D,{ }^{* *} \mathrm{p}<0.01,{ }^{* * *} \mathrm{p}<0.001$

ANOVA, followed by Tukey's multiple comparison test. ANOVA: Analysis of variance, BHT: Butylated hydroxytoluene, DPPH: 2,2-Diphenylpicrylhydrazyl FRAP: Ferric reducing ability, SD: Standard deviation 


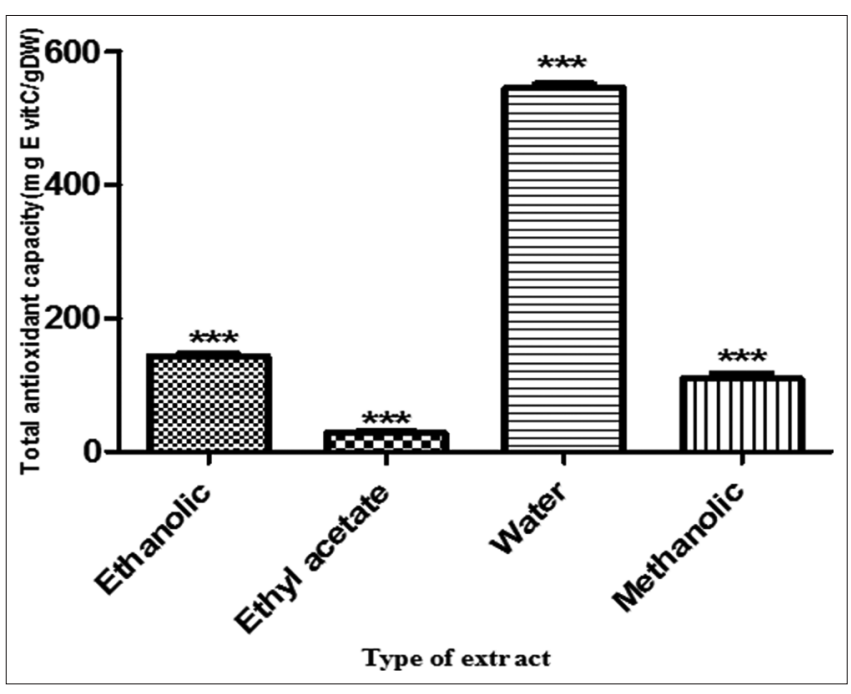

Fig. 1: Total antioxidant capacities of different extracts of Laurus nobilis. Results were expressed as mg equivalent Vitamin C/g dry weight. Each value represents mean \pm standard deviation of triplicate $(* * * p<0.001)$

Besides, the total amounts of flavonoids were determined by a colorimetric method using aluminum trichoride $\left(\mathrm{AlCl}_{3}\right)$ for all extracts. This amount was reported by mg equivalent Rutin/g DM. Thus, the results showed that the water, ethanolic, and methanolic extracts displayed a moderate values $101.51 \pm 1.51$ to $127.25 \pm 2.60$ mg equivalent rutin/g DM Table 3. Total phenols and flavonoids were significantly higher in all extracts of laurel.

\section{DISCUSSION}

The present study was carried out to demonstrate the antioxidant potential of $L$. nobilis $L$. Indeed, studies are limited in terms of evaluating the antioxidant activities as well as the total amounts of phenols and flavonoids in different laurel extracts in Morocco. Nevertheless, many researches were performed to evaluate the ability of different laurel extracts for trapping the free radical DPPH. Thus, the current aqueous extract $\left(\mathrm{IC}_{50}=0.06 \pm 0.0003 \mathrm{mg} / \mathrm{ml}\right.$ ) has a high ability to reduce free radical comparing to the ethanolic and the methanolic extracts of laurel, which are originated respectively from Portugal and Italy [12].

The extraction of laurel leaf method could affect the power of reducing the free radicals [19]. Indeed, our results showed that the aqueous extract is extremely rich in total phenols $494.86 \pm 3.62 \mathrm{mg}$ equivalent to gallic acid/g DM. These results are in agreement with several previous studies that showed the high availability of phenols in Laurel $[5,12,19]$. Therefore, reducing different kinds of oxygen and nitrogen species, as well as the free radicals, relates to phenolic compounds [20]. Hence, the quality of natural antioxidants is mainly based on the availability of phenolic compounds [21,22]. The antioxidant activity of the plant extracts would be expected to relate to the chemical composition [23-25]. Therefore, there is a certain correlation between the antioxidant activity and the total amount of phenols and flavonoids [26].

The antioxidant activity of extracts: Ethanolic, methanolic, aqueous, and ethyl acetate of L. nobilis L. species was examined in Morocco by different methods: Iron and molybdate reduction and the free radical trapping method. Overall, it was shown that water extract has a high antioxidant activity which could be compared or even higher to the standard. Laurel leaves represent an important antioxidant source of natural phenols and flavonoids which are beneficial to human public health. Indeed, the use of these substances may help in reducing chemical products which usually induce certain secondary effects. Hence, researches are needed for an advancing identification, isolation,
Table 3: Total phenolic and flavonoid compounds of different extracts of Laurier

\begin{tabular}{lll}
\hline Sample extracts & $\begin{array}{l}\text { Phenols equivalent } \\
\text { acid gallic } \mathbf{~ m g / g ~ D M}\end{array}$ & $\begin{array}{l}\text { Flavonoids equivalent } \\
\text { rutin } \mathbf{~ m g / g ~ D M}\end{array}$ \\
\hline Ethanolic & $284.11 \pm 3.71$ & $153.89 \pm 3.59$ \\
Methanolic & $133.32 \pm 1.71$ & $101.45 \pm 1.48$ \\
Ethyl acetate & $21 \pm 0.72$ & $9.59 \pm 0.58$ \\
Water & $494.86 \pm 3.62$ & $127.25 \pm 2.6$ \\
\hline
\end{tabular}

Results were expressed as mg GAE/g DM. Each value represents means \pm SD of triplicate $\left({ }^{* * *} \mathrm{p}<0.001\right)$. SD: Standard deviation

and purification of laurel compounds for further investigation at different levels (pharmaceutical, food, and cosmetic industries).

\section{CONCLUSION}

Accurately, L. nobilis L. extracts from Morocco demonstrated in vitro high antioxidant activity. A way to prevent food oxidation is the use of antioxidants. The synthetic antioxidant currently used in the food industry (BHA and BHT) has been found to possess several pernicious health effects. There is increasing interesting natural antioxidants, especially plant-derived antioxidant compounds. Numerous studies have shown that plant extracts represent a major source of compounds exhibiting strong antioxidant activity and that they can be used in curing many oxidative stress-related diseases such as cancer, diabetes, and cardiovascular. The results of the present work on antioxidant assays justified and partially supported the previous literature data and the popular usage of the tested plants. Further studies are required to investigate the in vivo efficacy of these extracts.

\section{ACKNOWLEDGMENTS}

The authors are thankful to University Sidi Mohamed Ben Abdellah, Fez, Morocco, for supporting this study.

\section{AUTHORS' CONTRIBUTIONS}

All the authors have contributed equally.

\section{CONFLICTS OF INTEREST STATEMENT}

The authors declare that there are no conflicts of interest.

\section{REFERENCES}

1. Pakash D, Singh BN, Upadhyay G. Antioxidant and free radical scavenging activities of phenols from onion (Allium cepa). Food Chem 2007;102:1389-93.

2. Toma CC, Olah NK, Vlase L, Mogosan C. Comparative studies on polyphenolic composition, antioxidant and diuretic effects of Nigella sativa L. (Black Cumin) and Nigella damascena L. (Lady-in-a-Mist) seeds. Molecule 2015;20:9560-74

3. Bajalan I, Mohammadi M, Alaei M, Pirbalouti AG. Total phenolic and flavonoid contents and antioxidant activity of extracts from different populations of lavandin. Ind Crops Prod 2016;87:255-60.

4. Ganie SA, Jan A, Muzaffar S, Zargar BA, Hamid R, Zargar MA, et al. Radical scavenging and antibacterial activity of Arnebia benthamii methanol extract. Asian Pac J Trop Med 2012;5:766-72.

5. Chmit M, Kanaan H, Habib J, Abbass M, Mcheik A, Chokr A, et al. Antibacterial and antibiofilm activities of polysaccharides, essential oil, and fatty oil extracted from Laurus nobilis growing in Lebanon. Asian Pac J Trop Med 2014;7S1:S546-52.

6. Sellami IH, Wannes WA, Bettaieb I, Berrina S, Chahed T, Marzouk B, et al. Qualitative and quantitative changes in the essential oil of Laurus nobilis L. Leaves as affected by different drying methods. Food Chem 2011;126:691-7.

7. Akcan T, Estevez M, Serdaroglu M. Antioxidant protection of cooked meatballs during frozen storage by whey protein edible films with phytochemicals from Laurus nobilis L. and Salvia officinalis. LWTFood Sci Technol 2017;77:323-31

8. Jemaa JM, Tersim N, Toudert KT, Khouja ML. Insecticidal activities of essential oils from leaves of Laurus nobilis L. From Tunisia, Algeria 
and Morocco, and comparative chemical composition. J Stored Prod Res 2012;48:97-104.

9. Khan A, Zaman G, Anderson RA. Bay leaves improve glucose and lipide profile of peoples with type 2 diabetes. J Clin Biochem Nutr 2009;44:52-6

10. Nayak S, Nalabothu P, Sandiford S, Bhogadi V, Adogwa A. Evaluation of wound healing activity of Allamanda cathartica. L. And Laurus nobilis. L. Extracts on rats. BMC Complement Altern Med 2006;6:12.

11. Afifi FU, Khalil E, Tamimi SO, Disi A. Evaluation of the gastroprotective effect of Laurus nobilis seeds on ethanol induced gastric ulcer in rats. J Ethnopharmacol 1997;58:9-14.

12. Speroni E, Cervellati R, Dall'Acqua S, Guerra MC, Greco E, Govoni P, et al. Gastroprotective effect and antioxidant properties of different Laurus nobilis L. Leaf extracts. J Med Food 2011;14:499-504.

13. Si W, Chen YP, Zhang J, Chen ZY, Chung HY. Antioxidant activities of ginger extract and its constituents toward lipids. Food Chem 2018;239:1117-25.

14. Oyaizu M. Studies on products of browning reactions: Antioxidative activities of product of browning reaction prepared from glucosamine. Jpn J Nutr 1986;44:307-15.

15. Prieto P, Pineda M, Aguilar M. Spectrophotometric quantitation of antioxidant capacity through the formation of a phosphomolybdenum complex: Specific application to the determination of Vitamine E1. Anal Biochem 1999;269:337-41.

16. Slinkard K, Singleton VL. Total phenol analysis: Automation and comparaison with manual methods. Am J Enol Viticult 1977;28:49-55.

17. Zhishen J, Mengcheng T, Jianming W. The Determination of flavonoid contents in mulberry and their scavenging effect on superoxide radicals. Food Chem 1999;64:555-9.

18. Dias MI, Barros L, Duenas M, Alves RC, Oliveira MB, SantosBuelga $\mathrm{C}$, et al. Nutritional and antioxidant contributions of Laurus nobilis L. Leaves: Wold be more suitable a wild or a cultivated sample. Food Chem 2014;156:339-46.

19. Muniz-Marquez DB, Martinez-Avila GC, Wong-Paz JE, BelmaresCerda R, Rodriguez-Herrera R, Aguilar CN. Ultrasound-assisted extraction of polyphenols from native plants in the Mexican deser. Ultrason Sonochem 2014;22:474-81.

20. Widyawati PS, Werdani YD, Setiokusumo C, Kartikasri A. In vitro antioxidant capacities and antidiabetic properties of Pluchea leaves and green tea mixtures at various proportions. Int $\mathbf{J}$ Pharm Parm Sci 2017;9:203-8

21. Stankovic N, Mihajilov-Krstev T, Zlatkovic B, Stankov-Jovanovic V, Mitic V, Jovic J, et al. Antibacterial and antioxidant activity of traditional medicinal plants from the Balkan peninsula. NJAS-Wagen J Life Sc 2016;78:21-8.

22. Stankovic MS. Total phenolic content, flavonoids concentration and antioxidant activity of Marrubium peregrinum L. Extracts. Kragujeval J Sci 2011;33:63-72.

23. Bimal S, Tank RS, Ram CK, Ganga PP. Assessment of antimicrobial and antioxidant activities of Amomum sublatum roxb of Nepal. Asian J Pharm Clin Res 2017;10:95-7.

24. Archnad D, Dixitha M, Santhy KS. Antioxidant and anti clastogenic potential of Piper longum L. Int J App Pharm 2015;7:11-4.

25. Renuka K, Devi VR, Subramanian SP. Phytochemical screening and evaluation of in vitro antioxidant potential of immature palmyra palm (Borassus flabellifer LINN.) fruit. Int J Pharm Pharm Sci 2018;10:77-83.

26. Silva LI, Karuppusamy A, Miyajima F, Violante IMP, Bieski IG, et al. Antimicrobial and antioxidant activities of selected plants used by populations from Juruena valley, legal amazon, Brazil. Int J Pharm Pharm Sci 2017;9:179-91. 